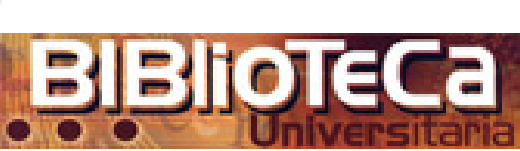

Biblioteca Universitaria

ISSN: 0187-750X

public@dgb.unam.mx

Universidad Nacional Autónoma de México

México

Morales Campos, Estela

F. W. Lancaster (Frederick Wilfrid Lancaster) In Memoriam

Biblioteca Universitaria, vol. 16, núm. 2, julio-diciembre, 2013, pp. 154-155

Universidad Nacional Autónoma de México

Distrito Federal, México

Disponible en: http://www.redalyc.org/articulo.oa?id=28529572006

- Cómo citar el artículo

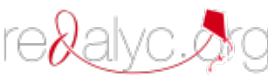

- Número completo

- Más información del artículo

- Página de la revista en redalyc.org

Sistema de Información Científica

Red de Revistas Científicas de América Latina, el Caribe, España y Portugal

Proyecto académico sin fines de lucro, desarrollado bajo la iniciativa de acceso abierto 


\section{F. W. Lancaster (Frederick Wilfrid Lancaster)}

\section{In Memoriam}

\section{Estela Morales Campos*}

$N$

acido en Durham, Inglaterra, en 1933, F. W. Lancaster fue un destacado investigador en el área de la Información y la Documentación. Sus principales aportaciones estuvieron dirigidas a la recuperación de la información, en la cual se ocupó tanto del control del vocabulario y su evaluación como de la indización. Recientemente, el 25 de agosto de 2013, falleció en Illinois, Estados Unidos, país donde radicó desde los 26 años de edad.

Lancaster se graduó como abogado en la Universidad de Northumbria, Newcastle, en 1955, donde también estudió Bibliotecología. En esa época fue bibliotecario de la red de bibliotecas públicas de Newcastle. En 1959, emigró a los Estados Unidos y se convirtió en bibliotecario senior en la biblioteca pública de Akron, Ohio. Inició su trayectoria como investigador en 1963, desarrollando una línea novedosa en esos años: la recuperación de información.

Trabajó como asesor en la Corporación Saul Herner y, durante esa década, participó tanto en el proyecto SHARP como en la evaluación de MEDLARS, el potente sistema de análisis y recuperación de publicaciones médicas de la National Library of Medicine. Su labor contribuyó de manera decisiva a explicar las razones por las cuales la recuperación de la información fallaba, pues encontró que los errores generados al respecto se debían a deficiencias en la indización, las estrategias de búsqueda y la interacción establecida entre el usuario y el sistema.

Su trabajo de investigación relativo a la evaluación de bibliotecas, sistemas de recuperación de información, control de vocabulario, indización, estructuras de resúmenes, índices de revistas, búsqueda en línea, necesidades de usuarios, programas de formación, colecciones de bibliotecas y, sobre todo, la evaluación como herramienta de gestión, es verdaderamente monumental. Alrededor de unas sesenta publicaciones de su autoría dan cuenta de esos enfoques.

Desde 1970 fue nombrado profesor asociado en el Posgrado de Ciencias de la Información y Bibliotecología de la Universidad de Illinois. Dos años más tarde obtuvo la titularidad (puesto que conservó hasta el año de su retiro, en 1992). En tres ocasiones, por cierto, le fue otorgado el Premio Fulbright para Enseñanza (situación excepcional, pues, usualmente, ese galardón es conferido un máximo de dos veces). La Universidad de Illinois, durante los últimos tres años de su carrera magisterial, lo nombró "University Scholar", el prestigioso reconocimiento otorgado a los profesores e investigadores de esa institución por méritos y talento académico.

Su tarea docente se extendió internacionalmente, pues fue responsable de cursos de educación continua y profesor visitante en universidades de países como Argentina, Brasil, China, Dinamarca, Alemania, India, Israel, Malasia, México, Namibia, Países Bajos, Noruega y Polonia, por referir algunos.

* Coordinadora de Humanidades e investigadora titular del Instituto de Investigaciones Bibliotecológicas y de la Información (IIBI). Coordinación de Humanidades, Universidad Nacional Autónoma de México (UNAM, Circuito Mario de la Cueva s/n, Zona cultural, Ciudad Universitaria, 04510 México, D.F., México. Correo electrónico: moce@unam.mx 
En nuestro país, fue invitado por la Dirección General de Bibliotecas (DGB) de la UNAM; sus conferencias y cursos impartidos, sin duda, estimularon de manera importante el desarrollo de la incipiente investigación bibliotecológica generada en la propia DGB; también, a partir de ese pequeño grupo de enseñanza, influyó en la profesionalización de los bibliotecarios mexicanos.

Otro de los espacios académicos desde el cual F. W. Lancaster impactó en la Bibliotecología nacional fue el Centro Universitario de Investigaciones Bibliotecológicas, CUIB (hoy Instituto de Investigaciones Bibliotecológicas y de la Información). En efecto, a mediados de la década de los noventa realizó una estancia académica en el CUIB, donde los investigadores interactuaron con él de diferentes formas; una de ellas fue a través del curso de actualización que impartió en esa época: Evaluación de bibliotecas y servicios bibliotecarios (1995). Asimismo, a petición del propio CUIB y bajo el sello editorial de esa dependencia universitaria, publicó el folleto Lineamientos para la recopilación de bases de datos (1996).

F. W. Lancaster fue autor de 15 libros, algunos de los cuales fueron nombrados libros del año por la American Society for Information Science (ASIS) o por la American Library Association (ALA). La primera, por ejemplo, lo galardonó en 1970 por su tratado en torno a la evaluación de sistemas documentales; en 1975 por su manual sobre recuperación de información en línea; en 1979 por Toward Paperless Information Systems (Hacia los sistemas de información sin papel), una obra de proyección profética, y en 1992 por Indización y resúmenes: teoría y práctica. Por su parte, la American Library Association, en 1978, premió su Evaluación de la biblioteca, obra considerada fundamental en los últimos 25 años dentro del ámbito de la información y la documentación.

Fue consultor en temas sobre almacenamiento y recuperación de la información en organizaciones de todo el mundo, tales como el Army Corp of Engineers, la Standard Oil, la UNESCO y el American Film Insititute.

La muerte de F. W. Lancaster -figura central en la aplicación de métodos novedosos a los sistemas de información- ha representado una gran pérdida en el mundo de la bibliotecología y la documentación. Su obra escrita es fuente de consulta para conocer innovaciones que, en su tiempo, potenciaron los servicios bibliotecarios en beneficio de los usuarios. os

\section{Fuentes:}

Amat, Carlos B. y Moreira, Alfonso R. F. W. Lancaster: entrevista realizada en Valencia el 14 de junio de 1994. Métodos de Información, sep., 1994, vol. 1, no. 1, p. 9-11.

Frederick Wilfrid Lancaster (September 4, 1933-August 25, 2013) [en línea]. Renner-Wikoff Chapel and Crematory. Obituaries. Herederos de F. W. Lancaster, nota luctuosa leída en la capilla y crematorio Renner-Wikoff, Urbana, Illinois, 25 de agosto de 2013. <http://www.renner-wikoffchapel.com/fh/obituaries/obituary.cfm?o_id=2204062\&fh_ $\mathrm{id}=10562>$

HAYES, Robert M. A tribute to F. Wilfrid Lancaster [en línea]. IDEALS, Illinois Digital Environment for Access to Learning and Scholarship. <http://hdl.handle.net/2142/9489>

Universidad Nacional Autónoma de México. Centro Universitario de Investigaciones Bibliotecológicas. Informe de actividades 1995. Elsa M. Ramírez Leyva, Blanca Estela Aldana Orozco, compiladoras. México: unam, Centro Universitario de Investigaciones Bibliotecológicas, 1996. 88 p. 